\title{
Progenitor Endothelial Cells in Pulmonary Arterial Hypertension
}

\section{Alexander Berezin}

Consultant of Therapeutic Unit, Internal Medicine Department, State Medical University for Zaporozhye, 26, Mayakovsky Av., Zaporozhye, Ukraine

"Corresponding author: Alexander Berezin, Professor, MD, PhD, Consultant of Therapeutic Unit, Internal Medicine Department, State Medical University for Zaporozhye, 26, Mayakovsky Av., Zaporozhye, Ukraine, Tel: 380612894585; E-mail: aeberezin@gmail.com

Received date: May 14, 2018; Accepted date: May 17, 2018; Published date: May 23, 2018

Copyright: $\odot 2018$ Berezin A, This is an open-access article distributed under the terms of the Creative Commons Attribution License, which permits unrestricted use, distribution, and reproduction in any medium, provided the original author and source are credited.

\begin{abstract}
Pulmonary artery hypertension (PAH) is common cardio-pulmonary phenomenon associated with higher risk of premature death and disability. Several previous studies have shown that decreased number of circulating endothelial progenitor cells (EPCs) correlated well with vascular remodeling and impaired pulmonary artery function. Moreover, a deep deficiency of EPC characterized a poor clinical outcomes in PAH individuals. There is large body of evidence regarding that the EPCs could be not just biomarker of endothelial dysfunction, but a target of PAH therapy. However, improvement of PAH severity associated with increasing number of circulating EPC with angiopoetic phenotype accompanying sildenafil care. The short communication is depicted the predictive role of EPCs in risk stratification in PAH patients and possibilities to use EPC-based care aimed improving clinical outcomes.
\end{abstract}

Keywords: Pulmonary artery hypertension; Endothelial progenitor cells; Stratification; risk; Biomarkers.

\section{Short Communication}

The pulmonary arterial hypertension $(\mathrm{PAH})$ is common cardiopulmonary phenomenon that occurs due to primary remodeling of small-to-moderate pulmonary arteries associated with vascular hypertrophy, perivascular fibrosis and stiffening, endothelial dysfunction and vascular occlusion, which lead to right ventricle heart failure and developing of multi organs insufficiency [1]. Prevalence of $\mathrm{PAH}$ has been demonstrated steadily growth worldwide and characterized increased mortality rate and disability rate [2]. According to current clinical statement PAH is defined as elevated mean pulmonary artery pressure $\geq 25 \mathrm{mmHg}$ at rest with simultaneously evidence of the presence of pre-capillary hypertension (end-expiratory pulmonary artery wedge pressure $\leq 15 \mathrm{mmHg}$ and a pulmonary vascular resistance $>3$ Wood units) measured during right heart catheterization [3]. Current conception of the pathogenesis of $\mathrm{PAH}$ based on an idea regarding self-supporting vascular remodeling and the thickness due to proliferation of smooth muscle cells with contractile phenotype, infiltration of intima and sub-intima with inflammatory and antigen-presenting cells ( $\mathrm{T}$ lymphocytes, natural killer cells, activated macrophages/mononuclears), developing of dysfunction of the endothelial cells and fibroblasts, which are resulted in uncoupling intracellular signal systems (calcium signaling, type II bone morphogenetic protein receptor gene-dependent signals, Akt/ endothelial nitric oxide synthases pathway, Jak-STAT and NOD-like receptor signaling) and their metabolic regulators (hypoxia, ischemia, inflammatory cytokines, autoantibodies) [4]. In this context, epigenetic dysregulation of DNA methylation, histone acetylation, and microRNAs co-existing PAH nature evolution is considered a leading factor in shaping of mitochondrial dysfunction that contributes to modification of cells involved in the vascular wall repair [5]. Therefore, chemical mediators of vasoconstriction, such hypoxia-inducible factor-1, endothelin-1, angiotensin-II, 5-hydroxytryptamine, and endotoxins, cause increasing vascular resistance, reducing pulmonary blood perfusion and directly trigger vascular remodeling and worsening vascular repair. The endothelial progenitor cells (EPCs) are key player in restoring of structure and function of vasculature, because they produce unique ability to (trans-) differentiate into cells with different phenotypes including mature endothelial cells and vascular wall smooth muscle cells and attenuate endothelial function [6]. Although EPCs are considered an important component of endogenous vascular repair system, epigenetic modification failed their angiopoetic capabilities and promotes progressive vascular injury [7].

Circulating endothelial progenitor cells (EPCs) are defined as CD45(-) progenitors that obligatory express endothelial cell antigens on their surface, i.e. CD31 (platelet/endothelial cell adhesion molecule-1), CD144 (vascular cadherin), CD309 (VEGF-receptor-2), and CD133 (prominin-like 1) [8]. According to ability to appear in fibronectin coated dish all EPCs were divided into early outgrowth EPCs or late outgrowth EPCs. The late outgrowth EPCs originated from peripheral blood mononuclears demonstrated CD31(+)CD146(+)CD105(+) and / or CD309(+) immune phenotype and had functional properties suitable for mature endothelial cells. EPCs are able to synthase and realize a wide range of active molecules (E-selectin, P-selectin), peptides and growth factors (vascular endothelial growth factor, fibroblast growth factor, granulocytemacrophage colony-stimulating factor) that modulate angiogenesis and improve vascular integrity and function [9]. It has established that there are several populations of EPCs with different proliferative activities and angiopoetic potencies that can be seized upon biological markers of vascular reparation, vessel injury and endothelial dysfunction.

PAH is characterizes endothelial cell dysfunction associating with decreased number and poor function of circulating EPCs with angiopoetic phenotypes that corresponds to a modulation of inflammatory genes, which are involved in vascular remodeling, fibrosis and hypertrophy (i.e., inetrleukin-6, TNF-alpha, Gal-3, growth-differentiation factor-15) [10-12]. Although there were strong positive association between exercise tolerance and circulating number of EPCs in PAH patients, there was not found significant relations 
Citation: Berezin A (2018) Progenitor Endothelial Cells in Pulmonary Arterial Hypertension . J Gen Pract (Los Angel) 6: 357. doi: 10.4172/2329-9126.1000357

Page 2 of 2

between concentration of EPCs and clinical status or hemodynamic features [13]. However, the successful treatment of PAH with sildenafil corresponds to increased circulating number of EPCs in PAH [14] Therefore, EPC-mediated therapy improves endothelial function, leads to decreasing of mean pulmonary artery pressure and index of pulmonary artery resistance and thereby ameliorates PAH [15]. Thus, identification of phenotypes of EPCs could be useful for prediction of poor clinical outcomes in $\mathrm{PAH}$ [16]. Additionally, the efficacy of $\mathrm{PAH}$ therapy could be assay with continuous monitoring of EPC number in peripheral blood, although the issue requires to be confirmed in large clinical trials.

In conclusion, deficiency of circulating EPCs associates with severity and prognosis of $\mathrm{PAH}$ and it could be predictive biomarker is patients suspecting PAH. Therefore, circulating levels of EPCs can consider as a target of PAH therapy, while this issue requires to be confirmed in large clinical trials.

\section{References}

1. Galiè N, Humbert M, Vachiery JL, Gibbs S, Lang I, et al. (2015) ESC scientific document group. ESC/ERS Guidelines for the diagnosis and treatment of pulmonary hypertension: The joint task force for the diagnosis and treatment of pulmonary hypertension of the European Society of Cardiology (ESC) and the European Respiratory Society (ERS): Endorsed by: Association for European Paediatric and Congenital Cardiology (AEPC), International Society for Heart and Lung Transplantation (ISHLT). Eur Heart J 46: 903-975.

2. Rosenkranz S (2015) Pulmonary hypertension 2015: Current definitions, terminology, and novel treatment options. Clin Res Cardiol 104: 197-207.

3. Simonneau G, Gatzoulis MA, Adatia I, Celermajer D, Denton C, et al (2013) Updated clinical classification of pulmonary hypertension. J Am Coll Cardiol 62: D34-41.

4. Thenappan T, Ormiston ML, Ryan JJ, Archer SL (2018) Pulmonary arterial hypertension: Pathogenesis and clinical management. BMJ 360: j5492.
5. Berezin A (2016) Epigenetics in heart failure phenotypes. BBA Clin 6: 31-7.

6. Crnkovic S, Marsh LM, El Agha E, Voswinckel R, Ghanim B, et al. (2018) Resident cell lineages are preserved in pulmonary vascular remodeling. J Pathol 244: 485-498.

7. Berezin AE (2017) Endothelial progenitor cells dysfunction and impaired tissue reparation: The missed link in diabetes mellitus development. Diabetes Metab Syndr 11:215-220.

8. Patel J, Donovan P, Khosrotehrani K (2016) Concise Review: Functional Definition of Endothelial Progenitor Cells: A Molecular Perspective. Stem Cells Transl Med 5: 1302-1306.

9. Zaccone V, Flore R, Santoro L, De Matteis G, Giupponi B, et al. (2015) Focus on biological identity of endothelial progenitors cells. Eur Rev Med Pharmacol Sci 19: 4047-63.

10. Plácido R, Cortez-Dias N, Robalo Martins S, Gomes Almeida A, Calisto C, et al. (2017) Prognostic stratification in pulmonary hypertension: A multi-biomarker approach. Rev Port Cardiol 36: 111-125.

11. Shao D, Perros F, Caramori G, Meng C, Dormuller P, et al. (2014) Nuclear IL-33 regulates soluble ST2 receptor and IL-6 expression in primary human arterial endothelial cells and is decreased in idiopathic pulmonary arterial hypertension. Biochem Biophys Res Commun.; 451: 8-14.

12. Chen H, Strappe P, Chen S, Wang LX (2014) Endothelial progenitor cells and pulmonary arterial hypertension. Heart Lung Circ 23: 595-601.

13. García-Lucio J, Tura-Ceide O, Del Pozo R, Blanco I, Pizarro S, et al. (2017) Effect of targeted therapy on circulating progenitor cells in precapillary pulmonary hypertension. Int J Cardiol 228: 238-243.

14. Favre S, Gambini E, Nigro P, Scopece A, Bianciardi P, et al. (2017) Sildenafil attenuates hypoxic pulmonary remodelling by inhibiting bone marrow progenitor cells. J Cell Mol Med 21: 871-880.

15. Yang JX, Pan YY, Zhao YY, Wang XX (2013) Endothelial progenitor cellbased therapy for pulmonary arterial hypertension. Cell Transplant 22: 1325-36.

16. Berezin AE (2016) Prognostication in Different Heart Failure Phenotypes: The Role of Circulating Biomarkers. J Circ Biomark. 5: 6 . 